\title{
COMUNICAÇÃO NÃO-VERBAL: REFLEXÕES ACERCA DA LINGUAGEM CORPORAL
}

\author{
Lúcia Marta Giunta da Silva* \\ Virginia Visconde Brasil** \\ Heloísa Cristina Quatrini Carvalho Passos Guimarães*** \\ Beatriz Helena Ramos de Almeida Savonitti* \\ Maria Júlia Paes da Silva****
}

SILVA, L.M.G.da; BRASIL, V.V.; GUIMARÃES, H.C.Q.C.P.; SAVONITTI, B.H.R.A.; SILVA, M.J.P.da. Comunicação não-verbal: reflexões acerca da linguagem corporal. Rev.latino-am.enfermagem, Ribeirão Preto, v. 8, n. 4, p. 5258 , agosto 2000 .

Buscamos com este estudo refletir sobre a importância da linguagem corporal, através da identificação do que um grupo de enfermeiras pós-graduandas, sabiam sobre o assunto. Analisamos o conteúdo dos relatos de onde emergiram cinco categorias: conceito, função, importância, significado e formas de manifestação da linguagem corporal. A linguagem corporal foi valorizada pelo grupo como uma forma complexa de interação interpessoal da qual temos pouca consciência, ocorrendo por vezes à margem do nosso controle. Tem por função expressar sentimentos, emoções e transmitir mensagens, cujos significados são influenciados pelo contexto. O conhecimento da linguagem corporal amplia nossa percepção profissional e é mais um instrumento para melhorar a qualidade da assistência de enfermagem.

UNITERMOS: comunicação não-verbal, linguagem corporal, enfermagem, cinésica

\section{INTRODUÇÃO}

A comunicação é um processo de interação no qual compartilhamos mensagens, idéias, sentimentos e emoções, podendo influenciar o comportamento das pessoas que, por sua vez, reagirão a partir de suas crenças, valores, história de vida e cultura.

No cotidiano profissional a enfermeira utiliza a comunicação para o desempenho de suas diversas atividades. Dentre estas, a sua função como educadora e prestadora de cuidados, bem como, ser elo de ligação entre a equipe multiprofissional e os diferentes serviços de cuidado indireto, exige da enfermeira um maior domínio da habilidade de comunicar-se. Assim, o uso consciente da comunicação tende a facilitar o alcance dos objetivos da assistência de enfermagem ${ }^{14}$.

Por considerarmos estas afirmativas essenciais para o aprimoramento de nossa competência profissional e como integrantes do Programa de Pós-Graduação da
Escola de Enfermagem da Universidade de São Paulo (EEUSP), participamos da disciplina "Comunicação na saúde do adulto: interação da linguagem verbal e do não verbal nas relações interpessoais", durante a qual nos foi solicitada a apresentação de um seminário sobre "Cinésica: a linguagem do corpo".

As discussões realizadas para a elaboração do referido seminário nos levaram a refletir sobre a importância da linguagem corporal e seus efeitos na relação enfermeira-paciente uma vez que, através dela, são transmitidas inúmeras mensagens nem sempre conscientes e/ou manifestas (validadas) verbalmente.

A comunicação pode ser realizada de forma verbal e/ou não-verbal. A comunicação verbal exterioriza o ser social e a não-verbal o ser psicológico, sendo sua principal função a demonstração dos sentimentos ${ }^{12}$.

Em geral, é atribuída maior relevância à comunicação verbal expressa pela linguagem falada ou escrita; entretanto, o homo sapiens sempre se comunicou

\footnotetext{
* Enfermeira. Mestranda da Escola de Enfermagem da Universidade de São Paulo. Professor Assistente da Faculdade de Enfermagem do Hospital Israelita Albert Einstein

** Enfermeira. Doutoranda da Escola de Enfermagem da Universidade de São Paulo. Professor Assistente da Faculdade de Enfermagem da Universidade Federal de Goiás

*** Enfermeira. Doutoranda do Departamento de Enfermagem da Universidade Federal de São Paulo. Pesquisadora Científica I do Instituto Dante Pazzanese de Cardiologia

**** Enfermeira. Professor Doutor do Departamento de Enfermagem Médico-Cirúrgica da Escola de Enfermagem da Universidade de São Paulo
} 
mesmo que através de grunhidos e gesticulações. BIRDWHISTELL 2 considera que "apenas $35 \%$ do significado social de qualquer interação corresponde às palavras pronunciadas, pois o homem é um ser multissensorial que, de vez em quando, verbaliza".

A comunicação não-verbal exerce fascínio sobre a humanidade desde seus primórdios, pois envolve todas as manifestações de comportamento não expressas por palavras, como os gestos, expressões faciais, orientações do corpo, as posturas, a relação de distância entre os indivíduos e, ainda, organização dos objetos no espaço. Pode ser observada na pintura, literatura, escultura, entre outras formas de expressão humana. Está presente no nosso dia-a-dia mas, muitas vezes, não temos consciência de sua ocorrência e, nem mesmo, de como acontece $e^{4,5,13,14}$.

A comunicação não-verbal, entendida como ações ou processos que têm significado para as pessoas, exceto a expressão verbal, é classificada por KNAPP ${ }^{8}$ em: paralinguagem (modalidades da voz), proxêmica (uso do espaço pelo homem), tacêsica (linguagem do toque), características físicas (forma e aparência do corpo), fatores do meio ambiente (disposição dos objetos no espaço) e cinésica (linguagem do corpo).

Considerando que a capacidade de ouvir e compreender o outro inclui não apenas a fala, mas também as expressões e manifestações corporais como elementos fundamentais no processo de comunicação, a Cinésica, ou seja, o estudo da linguagem corporal, assume um papel importante na decodificação das mensagens recebidas durante as interações profissionais ou pessoais.

A cinésica, também denominada cinética, foco central deste trabalho, foi estudada por BIRDWHISTELL ${ }^{2}$, antropólogo pioneiro em tentar compreender a linguagem do corpo. Ele se dedicou ao estudo dos movimentos corporais e não identificou qualquer expressão facial, atitude ou posição do corpo que tivesse o mesmo significado nas diversas sociedades. Considera que não há gestos ou movimentos corporais que possam ser considerados como símbolos universais e, que toda cultura tem seu repertório gestual.

Este mesmo autor estabeleceu alguns pressupostos para melhor compreensão da cinésica: 1) o contexto fornece o significado ao movimento ou expressão corporal; 2) a cultura padroniza a postura corporal, o movimento e expressão facial; 3) o comportamento dos membros de um grupo é influenciado pelas suas próprias atividades corporais e fonéticas; 4) os comportamentos têm significados culturalmente reconhecidos e validados. Ele sugere que "enquanto o comportamento do movimento corporal é baseado na estrutura fisiológica, os aspectos comunicativos deste comportamento são padronizados pela experiência social e cultural. O significado de tal comportamento não é tão simples que possa ser colocado num glossário de gestos" e, só pode ser percebido a partir de um exame das estruturas padronizadas do sistema de movimentos corporais, de como se manifesta numa situação social particular.

Assim sendo, podemos dizer então que apenas o movimento do corpo não traduz o significado da mensagem, havendo necessidade de inseri-lo num contexto, permitindo que um mesmo gesto tenha diferentes significados nas diversas sociedades. Entretanto, segundo DAVIS ${ }^{5}$, há uma polêmica entre os pesquisadores de expressões faciais sobre a existência ou não de gestos universais.

Em contraposição ao que foi defendido por BIRDWHISTELL $^{2}$, os estudos de EKMANN $^{6}$ comparando culturas defendem a existência de gestos que podem ser descritos como universais. Seu principal argumento é um trabalho realizado com crianças portadoras de cegueira congênita, que adotam expressões típicas de raiva, medo, tristeza, alegria, mesmo sem poder imitar quem as rodeia. Contudo, esse mesmo autor sugere que em toda cultura há "regras demonstrativas", que determinam a adequação das expressões em diferentes situações. Cada cultura, além de regras próprias dispõe de estilos faciais próprios.

Os gestos são compreendidos de diversas formas nas diferentes culturas. Só existe um gesto semelhante em qualquer lugar do mundo - o sorriso ${ }^{5}$, muito embora essa semelhança não deva ser entendida como uma expressão invariável de prazer ou alegria, uma vez que seu significado difere de cultura para cultura e, ainda, conforme o contexto da situação, pode significar surpresa, prazer, desaprovação, ironia, superioridade, desprezo, agressividade, maldade, entre outros.

Como podemos observar, a linguagem do corpo diz muitas coisas tanto para nós quanto para aqueles que nos rodeiam. O corpo é, antes de tudo, um centro de informações e, segundo GAIARSA 7 "aquilo que de mim eu menos conheço é o meu principal veículo de comunicação". Este mesmo autor sugere que um "observador atento consegue ver no outro quase tudo aquilo que o outro está escondendo - conscientemente ou não. Assim tudo aquilo que não é dito pela palavra pode ser encontrado no tom de voz, na expressão do rosto, na forma do gesto ou na atitude do individuo".

Muitas vezes ocorrem situações nas quais o profissional procura controlar suas expressões faciais na tentativa de amenizar, disfarçar ou neutralizar um sentimento, a fim de não interferir na relação terapêutica.

A esse respeito $\mathrm{EKMAN}^{6}$ desenvolveu um estudo com estudantes de enfermagem solicitando-lhes que, após assistirem um filme com cenas desagradáveis, descrevessem-nas como se fossem agradáveis. Seu objetivo foi identificar quais os sinais do rosto e/ou movimento do corpo indicavam que o estudante mentia. 
Seus resultados mostraram que é possível fingir uma expressão alegre, zangada ou triste, porém, a dificuldade está em fazer esta expressão surgir de uma hora para outra, mantê-la ou mesmo escondê-la.

Da mesma forma a habilidade em realizar uma leitura consciente dos diferentes gestos, pode ser obtida com treinamento e tende a facilitar o reconhecimento de um sentimento ou emoção, ainda que sutilmente expressos.

Embora não seja nossa pretensão esgotar o assunto, esperamos que as reflexões deste estudo destaquem a importância do conhecimento sobre linguagem corporal, por meio da identificação do que enfermeiras pós-graduandas conhecem a esse respeito. Estas reflexões poderão favorecer a ampliação da nossa percepção profissional, sendo mais um elemento para melhorar a qualidade da assistência de enfermagem. À medida que refletimos sobre o nosso fazer buscamos a excelência do cuidado, da nossa prática profissional, da competência para o cuidado. Os reflexos do cuidado enquanto responsabilidade da enfermeira exigem um controle dessa qualidade, o que envolve também uma avaliação de como a nossa linguagem corporal pode estar influenciando no resultado desse cuidado.

\section{METODOLOGIA}

A estratégia utilizada para desenvolver este estudo foi solicitar às vinte alunas presentes à apresentação do seminário sobre Cinésica, que respondessem a uma pergunta por escrito, antes da exposição teórica do conteúdo.

Esclarecemos que era nosso objetivo refletir sobre a linguagem corporal e pedimos permissão para que suas respostas fizessem parte dessa reflexão, esclarecendo que não havia necessidade de identificação pessoal. Obtivemos seu consentimento oral e todas as alunas responderam à pergunta, caracterizando $o$ "consentimento esclarecido" 16 ou "claramente expresso", do grupo.

A pergunta feita às pós-graduandas foi: " $O$ que sabe sobre linguagem corporal?"

As respostas foram escritas pelos próprios sujeitos em fichas posteriormente analisadas pelas autoras.

Vale a pena ressaltar que o assunto já havia sido abordado de forma genérica em aulas anteriores sobre comunicação não-verbal.

A análise foi realizada visando identificar a presença de características expressas no relato dos sujeitos, tendo em vista o objetivo do estudo. Desta forma foi possível, após várias leituras, "fazer inferências através da identificação sistemática e objetiva de características especificadas no interior do texto",", explicando o processo de opinião de forma mais clara e objetiva, ou seja, atribuindo significados diversos que permitiram outra leitura da mensagem, aquela determinada pelo objeto de estudo ${ }^{1,9}$.

O conteúdo dos relatos foi codificado em categorias, que são abstrações dos fenômenos observados nos dados. Para operacionalizá-las, selecionamos partes que melhor representavam os fatos.

As categorias emergiram dos relatos e os dados foram agrupados por similaridade em: Conceito, Função, Importância, Significado e Formas de Manifestação da linguagem corporal.

Os relatos foram apresentados nos resultados na forma em que foram registrados nas fichas pelas enfermeiras, aparecendo em destaque e entre aspas.

\section{APRESENTAÇÃO E ANÁLISE DOS RESULTADOS}

As categorias identificadas foram:

\section{1 - Conceito}

Foi possível identificar no relato das enfermeiras, uma tentativa de conceituar a linguagem corporal. Foram apontados o conjunto de expressões e movimentos do corpo como uma forma complexa de comunicar-se, de interagir e de manifestar sentimentos, vontades, emoções, de exteriorizar conteúdos internos:

“... conjunto de expressões do corpo... meio de comunicação mais efetivo...”

“... é a mensagem do corpo durante a comunicação... é todo gesto expresso pelo ser humano ..."

“... o conjunto dos gestos, expressões do согро..."

"São expressões, manifestações externas, corporais dos conteúdos internos..."

"São as expressões do corpo. O movimento que se faz palavra para aqueles que estão envolvidos na comunicação."

"... é um veículo através do qual nos comunicamos..."

“... significado do movimento, a expressão corporal..."

"Todas as manifestações através do corpo..."

" É a forma não-verbal de manifestarmos nossos sentimentos, emoções, vontades..."

"É uma forma complexa de linguagem nãoverbal..." 
“... é a forma do corpo expressar o que sente, pensa elou age ... 'ECOAR'..."

"... expressão do nosso corpo..."

A literatura não conceitua especificamente a linguagem corporal. Os conceitos encontrados são amplos e dizem respeito à comunicação não-verbal de modo geral. CORRAZE" lembra que "quando se mostra a existência de formas universais nas mensagens nãoverbais, não se pode deixar de pensar que a cinética só estuda uma parte delas". Isto é, para compreender o processo de comunicação não-verbal, é necessário muito mais do que apenas a linguagem do corpo. Há que se considerar o tom da voz, o espaço utilizado pelo homem, o toque e os fatores do meio ambiente; todos eles inseridos em um determinado contexto. O significado atribuído vai depender de todos estes elementos interrelacionados.

Chamou nossa atenção o relato: "é o movimento que se faz palavra...". Talvez, ele encerre a essência da linguagem corporal, assinalando que o corpo se comunica mesmo destituído do verbo.

\section{2 - Função}

A função da linguagem corporal foi identificada pelas enfermeiras como uma forma de expressar através do corpo emoções, sentimentos, reações e de transmitir mensagens como expressam os relatos abaixo:

"...para comunicar-se com o meio..."

“...Transmite mensagens, emoções..."

“...demonstrar sua emoção, reação diante de uma situação.”

“...se expressar, expressar muitas das emoções

... expressar os sentimentos."

“...expressam 'milhões' de coisas, de acordo com o contexto, cultura etc..."

"...complementa a comunicação verbal...movimento corpóreo, que tentam expressar e ter algum significado."

"...expressam ou comunicam..."

“...traduz algo a ser comunicado...proporciona evolução nas relações."

"...transmitindo ou decodifindo alguma mensagem ...”

Um dos pressupostos básicos para compreensão da cinésica, segundo BIRDWHISTELL ${ }^{2}$, é que "determinado comportamento, ou seja, a atividade corporal visivel, encerra significados socialmente reconhecidos e válidos. Os sinais identificados pela pessoa são igualmente captados por seu grupo". Isto pode ser observado no seguinte relato:

"Observando as pessoas podemos deduzir pelo modo de vestir, andar, falar, a postura, se estão ou são, alegres, tristes, cansadas, ativas, adinâmicas."
Muitas vezes, a comunicação não-verbal modifica o significado da verbal, ou seja, a mensagem verbal é contraditória ao que é expresso pela comunicação não-verbal entre os indivíduos.

SILVA $^{13}$ considera o rosto como o melhor "mentiroso" não-verbal. Ele é a parte do corpo que as pessoas mais tentam controlar, o que é possível conseguir através de treino. Alguns relatos demonstram essa afirmativa:

“... mesmo que utilizemos palavras muitas vezes que não condizem com o que realmente pensamos, a feição do rosto, gestos, movimentos podem muitas vezes mostrar o oposto."

“... expressar muitas vezes mais do que a gente consegue expressar através das palavras."

Podemos afirmar também, que é imperiosa no profissional, a habilidade em perceber manifestações nãoverbais no comportamento dos pacientes, que muitas vezes negam o verbal.

É interessante observar como várias enfermeiras citaram as emoções em seus relatos:

“... Transmite...emoções..."

“...se expressar, expressar muitas das emoções..."

“...expressa sem dúvida todas as nossas emoções...”

"...demonstra sentimentos, emoções..."

“...demonstramos emoções que trazem embotadas as afetividades."

As emoções foram estudadas por SILVA ${ }^{10}$ descrevendo sete emoções consideradas puras: alegria, raiva, nojo, medo, tristeza, surpresa, desprezo, por meio das configurações faciais e de arranjos de sinais, principalmente, na testa, olhos e boca. Como a face é a parte mais exposta do corpo humano, e é onde as emoções são principalmente demonstradas, as enfermeiras precisam estar atentas às alterações que ocorrem no rosto dos pacientes. Podem sugerir indícios de emoções não expressas verbalmente, permitindo o cuidado individualizado e holístico.

\section{3 - IMPORTÂNCIA}

A importância da linguagem corporal foi ressaltada por algumas enfermeiras como essencial nas relações interpessoais, assim como a necessidade de ser compreendida e valorizada porque "proporciona evolução nas relações":

“...É preciso valorizá-la, observá-la e utilizála."

“...É fundamental no processo de comunicação."

“...É essencial na comunicação!!!” 
“...a interpretação desses gestos é muito rica..."

"...influencia muito no processo de comunicação.”

Como profissionais em constante interação com outras pessoas, devemos nos lembrar das diferentes crenças, valores e culturas que permeiam estas relações e estar conscientes da influência que sofremos e exercemos, mutuamente, através da linguagem corporal.

No estudo de SILVA ${ }^{11}$ foi evidenciado o pouco conhecimento que as enfermeiras têm sobre comunicação não-verbal. Essa mesma autora, em $1996^{13}$, sugere que o conhecimento do não-verbal pode favorecer a percepção das enfermeiras quanto aos sentimentos, emoções, dúvidas e dificuldades não verbalizadas pelo paciente. Além disso, potencializa a habilidade de comunicação deste profissional, pois "todo ser humano precisa aprender a lidar consigo mesmo e com os outros".

Esta consciência é fundamental, principalmente se lembrarmos da função educadora da enfermeira, como motivadora de mudanças de comportamentos nos aspectos de saúde. Quando nos conhecemos e percebemos que podemos ser afetados pelo comportamento do outro, compreendemos porque o paciente pode reagir de diferentes maneiras a um mesmo estímulo.

\section{4 - Significado}

As enfermeiras relataram o que, para elas, representa a linguagem corporal - uma valoração subjetiva do que significa expressar-se através do corpo.

Um dos pontos ressaltados foi que o corpo é veículo das emoções e sentimentos puros, nem sempre conscientes, que exprimem a essência do ser:

"...o corpo "fala"..."

“... Linguagem da alma, do sentimento puro e limpo ... que encerram muitas conotações sociais, culturais, o viver o dia-a-dia de cada um, e a demonstração de amor em geral e outros sentimentos."

“... O corpo tem sua linguagem própria..."

“...O corpo é a expressão concreta de sua essência, emoções e pensamentos... é a expressão real, pura das nossas emoções."

"...é a linguagem que podemos considerar verdadeira por não termos controle consciente sobre a mesma."

Percebemos ainda, que emergiu do relato "os outros conhecem melhor nossa linguagem corporal do que nós mesmos", uma reflexão sobre a pouca consciência que temos sobre a nossa linguagem corporal. É importante estarmos atentas às reações que provocamos nos outros para que possamos caminhar em direção ao auto-conhecimento.
De acordo com STEFANELLI ${ }^{14}$ "o homem age com base na significação que os fatos têm para ele ... a significação é conseqüência da interação social que o homem experimenta com seus semelhantes ...e é manipulada e modificada por meio de um processo interpretativo".

Baseadas nestes pressupostos e nos relatos das enfermeiras, podemos inferir que o conteúdo apresentado anteriormente na disciplina influenciou na interpretação e valorização da linguagem corporal, o que possivelmente determinará modificação nas suas atuações profissionais e relações interpessoais.

\section{5 - Formas de manifestação}

Dentre as possibilidades de formas de manifestação da linguagem corporal relatadas, aparece com maior freqüência a intenção consciente e/ou inconsciente de expressar-se através do corpo.

CORRAZE ${ }^{4}$ afirma que "no que concerne à intenção consciente, percebe-se que o homem, nas circunstâncias habituais da vida, tem muito pouco domínio sobre as suas comunicações não-verbais". Refere, ainda, que temos pouca consciência dos gestos que utilizamos, não estando atentas à forma como os fazemos.

“...podem ser conscientes e inconscientes..."

"...conscientes ou inconscientes."

“...intencionalmente ou não."

“...controlável ou não."

“...voluntários e involuntários, conscientes e inconscientes."

"...de forma consciente ou não; através de nossos gestos, posturas corporais."

“...conscientes ou não."

$\mathrm{O}$ estudo de BIRDWHISTELL ${ }^{2}$ concluiu que num nível abaixo da consciência ocorre parte da comunicação humana, local onde é indireta a importância das palavras.

Os relatos destacaram também, que a comunicação corporal se dá continuamente e que o contexto em que ocorre deve ser considerado:

“...manifesta-se continuamente em nosso existir, e de acordo com o contexto em que vivemos."

“...que pode ser consciente ou não, que envolve nossos gestos, posturas, emoções e sentimentos em determinado contexto..."

"...o movimento deve ser visto no todo do corpo."

"...o tempo todo, com as pessoas que nos cercam..."

"...nosso corpo manifesta durante todo período...mesmo quando estamos de olhos 
fechados conseguimos passar uma mensagem

para alguém."

É importante lembrar aqui que em seu estudo BIRDWHISTELL ${ }^{2}$ estabeleceu, dentre seus pressupostos básicos, que o significado atribuído ao movimento ou expressão corporal é fornecido pelo contexto.

Outro ponto salientado pelas enfermeiras como elementos utilizados para manifestar a linguagem corporal, foram os gestos, movimentos, posturas e sinais faciais.

“...são movimentos realizados durante a fala ou um gesto."

"...através dos movimentos posturas e gestos do corpo..."

"...através de movimentos..."

“...engloba todas as manifestações do movimento corpóreo... facial e sinais...”

"...gestos, dança, movimentos de caminhar e acomodar-se, o simples movimento de olhos..."

"...através da mímica facial..."

“...através do rosto, do olhar, do sorriso, dos gestos das nossas mãos, pernas e postura corporal".

Estes relatos estão de acordo com as descrições da literatura sobre como a linguagem corporal se manifesta $^{4,5,13,14}$.

\section{CONSIDERAÇÕES FINAIS}

A partir da categorização foi possível evidenciar que a linguagem corporal é uma forma complexa de interação interpessoal, da qual temos pouca consciência, ocorrendo por vezes, à margem do nosso controle.

Tem como função expressar sentimentos, emoções, reações e transmitir mensagens. Manifesta-se de forma natural, intuitiva e continuamente, mas é influenciada pelo contexto e pelas diferentes culturas.
Esta visão do grupo demonstrou uma consonância com a literatura, evidenciando que estão sensibilizadas e mais receptivas ao aprendizado da comunicação. Isto não pode ser generalizado, pois os relatos surgiram no âmbito restrito da disciplina, além disto, a linguagem corporal ainda não é um tema muito discutido na formação profissional.

A formação acadêmica tende a fazer com que o profissional de enfermagem busque controlar a expressão de seus sentimentos e emoções, de forma a não interferir no seu desempenho cotidiano. Porém, a convivência diária com situações de dor, morte, mutilações entre outras, não só são desgastantes como geram conflitos diários, justificados apenas por uma tentativa de "controle" que excede os limites pessoais e profissionais.

Entretanto, esta mesma formação enfatiza a atenção às necessidades psicossociais dos pacientes. Questionamos se um indivíduo que necessita suprimir os próprios sentimentos e emoções, não se torna, com o passar do tempo, insensível à percepção das manifestações não-verbais expressas por aqueles sob seus cuidados. Poderíamos dizer, então, que os sentimentos e emoções tanto do paciente, quanto da enfermeira, não estão sendo adequadamente valorizados durante a interação.

A trajetória em direção à consciência da importância da linguagem corporal pode modificar este cenário, tornando possível transformar as interações em situações de "troca", que venham a ser enriquecedoras para os envolvidos no processo de comunicação.

Entendemos que a busca de uma "praxis" reflexiva é que resgata e valoriza a enfermagem na construção de seu conhecimento. Assim, a comunicação é um dos instrumentos que deve ser utilizado pela enfermeira, a fim de ampliar sua capacidade de perceber as mensagens implícitas ou explícitas, que permeiam a relação enfermeira-paciente e são fundamentais para a assistência de enfermagem.

\section{NON-VERBAL COMMUNICATION: REFLECTIONS ON BODY LANGUAGE}

The present study aimed to reflect on the importance of body language through the identification of what a graduate nursing group knew about this topic. We analyzed the contents of reports from which five categories emerged: concept, function, importance, meaning and forms of body language manifestation. The group valued body language as a complex way of interpersonal interaction that sometimes occurs out of our control and of which we have little conscience. It has the function of expressing feelings, emotions and transmitting messages whose meanings are influenced by context. Body language knowledge increases our professional perception and it is one more instrument to improve nursing assistance quality.

KEY WORDS: non-verbal communication, body language, nursing, kinesics 
grupo de enfermeras, estudiantes de pos-grado, si saben sobre dicho asunto. Analizando el contenido de los relatos, de donde surgieron cinco categorías: concepto, función, importancia, significado y formas de manifestación del lenguaje corporal. El lenguaje corporal fue valorizado por el grupo, como una forma compleja de interacción inter-personal, de la cual tenemos poca conciencia, ocurriendo algunas veces al margen de nuestro control. Tiene por función expresar sentimientos, emociones y transmitir mensajes, cuyo significado es influenciado por el contexto. El reconocimiento del lenguaje corporal amplía nuestra percepción profesional y es un instrumento más para mejorar la calidad de la asistencia de enfermería.

TÉRMINOS CLAVES: comunicación no verbal, lenguaje corporal, enfermería, cinésica

\section{REFERÊNCIAS BIBLIOGRÁFICAS}

01. BERELSON, B. Content analysis. In: LINDSEY, G.(org.) Handbook of social psychology. Massachusetts: Addison-Wesley, 1951. v. 1. p. 489.

02. BIRDWHISTELL, R.L. Kinesics and context: essays on body motion communication. 4.ed. Philadelphia: UPP (University of Pensylvania Press), 1985.

03. CONTANDRIOPOULOS, A.P. et al. Saber preparar uma pesquisa: definição, estrutura, financiamento. 2. ed. São Paulo-Rio de Janeiro: Hucitec Abrasco, 1997.

04. CORRAZE, J. As comunicações não-verbais. Rio de Janeiro: Zahar, 1982.

05. DAVIS, F. A comunicação não-verbal. 6. ed. São Paulo: Summus, 1979.

06. EKMAN, P. Darwin and facial expression: a century of research in review. New York: Academic Press, 1973. Cap. 4, p. 169-221: cross-cultural studies of facial expression.

07.GAIARSA, J.A. A estátua e a bailarina. 3. ed. São Paulo: Ícone, 1995.

08. KNAPP, M.L. La comunicación no verbal: el cuerpo y el entorno. Barcelona: Paidós, 1980.

09. ROSEMBERG, F. Da intimidade aos quiprocós: uma discussão em torno da análise de conteúdo. Cad. CERU, São Paulo, n. 16, p. 70-5, novembro 1981.
10. SILVA, A.A. Julgamento de expressões faciais de emoções: fidedignidade, erros mais freqüentes e treinamento. São Paulo, 1987. 260 p. Tese (Doutorado) - Instituto de Psicologia, Universidade de São Paulo.

11. SILVA, M.J.P. A percepção das enfermeiras sobre a comunicação não-verbal dos pacientes. São Paulo, 1989. 113p. Dissertação (Mestrado) Escola de Enfermagem, Universidade de São Paulo.

12. Construção e validação de um programa sobre comunicação não-verbal para enfermeiros. São Paulo, 1993. 108p. Tese (Doutorado) - Escola de Enfermagem, Universidade de São Paulo.

13. Comunicação tem remédio: a comunicação nas relações interpessoais em saúde. 2. ed. São Paulo: Gente, 1996.

14. STEFANELLI, M.C. Comunicação com o paciente: teoria e ensino. São Paulo: Robe, 1993.

15. STONE, P.J.; HOLSTI, O. Content analysis. In: LINDSEY, G.(org.) Handbook of social psychology. Massachusetts: Addison-Wesley, 1968. v. 2. p. 30.

16. VIEIRA, S.; HOSSNE, W.S. Pesquisa médica: a ética e a metodologia. São Paulo: Pioneira, 1998. 